Pensamiento Crítico Vol. 21, № 2, pp. 127 - 144

\title{
Una apreciación sobre la influencia de la evolución del mercado mundial en la producción minerometalúrgica del $\mathrm{Cu}$, $\mathrm{Pb}$ y $\mathrm{Zn}, 1995-2013$
}

An assessment of the influence of global market developments in the metal mining production of $\mathrm{Cu}, \mathrm{Pb}$ and $\mathrm{Zn}, 1995-2013$

[Recepción: Setiembre de 2016 / Conformidad: Octubre de 2016]

Ysaac Ospino Edery ${ }^{1}$

\section{RESUMEN}

La presente investigación nos lleva a apreciar, de manera inicial, la evolución del marco legal en el que se ha desenvuelto nuestra actividad minerometalúrgica, entre los años 1992 y la actualidad, así también nos da una perspectiva microeconómica de la oferta y demanda como producción y exportaciones, las que tienen un incremento sustantivo en sus volúmenes como resultado de las inversiones llevadas a cabo luego de la implementación de una legislación promocional y liberal, así como por los elevados precios registrados en el mercado de metales del cual formamos parte.

1 Profesor asociado y miembro del Instituto de Investigaciones de la Facultad de Ciencias Económicas de la UNMSM. Estudios de doctorado Gestión Económica Global y economista de la UNMSM. Magíster en Docencia Universitaria. UNEEGV. 


\title{
Pensamiento Crítico Vol. ᄅl, № 2
}

Se considera, finalmente, la implicancia y la evidencia empírica de la relación que se da entre la producción minerometalúrgica de los no ferrosos y la evolución del mercado mundial, entendida como las diferentes manifestaciones del ciclo económico expresado en la evolución del PBI por la que atraviesan las principales economías de los países demandantes de concentrados y refinados.

Palabras clave: Concentrados mineros, refinados, comercialización de producción minero metalúrgica, empírica.

\begin{abstract}
The present investigation, leads us to appreciate the evolution of the Legal framework in which our mining metallurgical activity has developed its initial way, between the years 1992 and the present. Likewise, a microeconomic perspective of supply and demand such as production and exports, the same ones that have a substantive increase in volumes as a result of the investments carried out after the implementation of promotional and liberal legislation, as well as by high prices registered in the market of metals of which we are part.

Finally, the implication and empirical evidence of the relationship that is given between the production metal mining of the not ferrous and the evolution of the world market is considered. Understood as different manifestations of the economic cycle in the evolution of GDP facing the main demanding country economies of concentrates and refined.
\end{abstract}

Keywords: Mining concentrates, refined, marketing of production, miningmetallurgical, empirical.

\section{Introducción}

Los precios de los minerales, concentrados y refinados no ferrosos más representativos para nuestra economía (cobre, zinc y plomo) son comúnmente el reflejo de las condiciones que imperan en cada momento en el mercado mundial, así como por las diferentes etapas del ciclo económico por las que atraviesan hoy las principales regiones industrializadas demandantes de producciones minerometalúrgicas, a lo que se agrega la evolución y la innovación tecnológica que las afecta. En el que participan compradores y vendedores de toda magnitud, influenciando de manera decisiva en las 


\section{Ysaac Ospino Edery}

fluctuaciones, de la oferta de la demanda y en la constitución de los precios, así como en su estabilidad, los que actúan en un mercado con estructura y carácter complejo.

Es así como los grandes compradores (China, EE.UU., RFA) ${ }^{2}$ y otros juegan un papel decisivo en el funcionamiento del mercado mundial, donde los efectos de las situaciones políticas, económicas, financieras que atraviesan sus economías repercuten en las diferentes industrias que demandan producciones minerometalúrgicas.

Tenemos que diferenciar que la estructura de la demanda se aprecia como la de concentrados y refinados, la primera constituida por la actividad de las fundiciones y refinerías, de característica más estable e inelástica en el corto plazo y, en términos de participantes, cuantificable fácilmente, al ser menor su número y la segunda por la industria en general de muchos participantes y de difícil cuantificación ${ }^{3}$.

Se tiene que en los últimos 50 años el Perú se ha venido ubicando como uno de los mayores productores y exportadores a nivel mundial de productos mineros, siendo los de cobre, zinc y plomo (no ferrosos primarios) en sus formas de concentrados, fundidos y refinados ${ }^{4}$; no obstante, en aquellos departamentos donde se ubicaron y se ubican las más importantes inversiones foráneas en minería, sus poblaciones presentan índices de desarrollo humano muy deprimidos, así como niveles de pobreza sustantivos, que no se ha visto modificada ${ }^{5}$.

Así mismo es sabida y reconocida la contribución de la explotación y exportación de la producción minera, para la economía de nuestro país (entre los años 2010 y 2013 esta participación se ha ubicado alrededor del 60\% del total exportado, siendo al principio de nuestro periodo de análisis alrededor de $45 \%)^{6}$, situación que también nos indica cuán vulnerables y dependientes somos de un mercado externo en el cual

2 Según la National Bureau of Statistics 2013, China, EEUU, y Alemania, importan el 10\%, 9\% y 5\% del comercio mundial.

3 En el caso del cobre en su forma de refinado, según estimaciones de Cochilco (Corporación Chilena del Cobre), para el año 2013, se prevé una demanda mundial de más de 21 millones de TM, teniendo a los mercados de la China, países de la Unión Europea, EEUU y Japón, como los de mayor participación.

4 Para el año 2013, el Perú ocupa el 3 y 4 en el Ranking Mundial como productor de Zinc y Plomo. Mientras que en Cobre el 3, según informa el Ministerio de Energía y Minas (Anuario Minero).

5 De acuerdo al Compendio Estadístico del INEI para el año 2013, el IDH es de 0.368 para Bolognesi en Áncash, 0.531 para Colquijirca en Cerro de Pasco y 0.603, para Yauli en Junín, con una pobreza total de $61.1,66.1$ y 57.5 , respectivamente.

6 Memorias BCR. Anuarios Estadísticos MEM (2012). 


\section{Pensamiento Crítico Vol. ᄅl, № 2}

solo participamos como primario exportadores, sin tener mayor margen de decisión o maniobra en la fijación de las cotizaciones de nuestros minerales, concentrados y metales ${ }^{7}$.

La actividad minera se constituye en el cuarto sector en importancia en la estructura del PBI total, tenemos así que este indicador registra un crecimiento de alrededor de un 4.5 veces desde mediados de la década de los noventa hasta el año 2013, mientras que el PBI minero aumenta en cerca de 9.5 veces en el mismo periodo. También, se registra que el valor de las exportaciones de los no ferrosos primarios dentro del total de las exportaciones mineras, en nuestro periodo de análisis se sitúa en más de un $30 \%$ del total obtenido por este concepto.

El monto de las remesas por esta actividad de comercio presenta una tendencia creciente, como resultado de la mayor producción registrada desde inicios de los años 2000 , resultante de la privatización de las concesiones mineras y las refinerías, la puesta en operación de nuevos proyectos mineros, así como el incremento de producciones de minerales de leyes marginales, ampliación que también se ve determinada ante el aumento de los precios que se registran para la mayoría de los metales, los cuales, como es sabido, se forman en el mercado externo ${ }^{8}$.

La búsqueda de menas minerales provoca nuevas áreas de expansión de las grandes empresas multinacionales (corporaciones), que se localizan en aquellas regiones que les brindan las mayores rentabilidades a su capital (inversión extranjera directa). Lo anterior trae como consecuencia que las inversiones en la industria minera se direccione hacia regiones del tercer mundo, donde la geología presenta grandes potenciales y la pobreza de sus pueblos, sumada al requerimiento de capitales para su explotación (carencia de ahorro interno), puede determinar menores resistencias a actividades no sustentables, incrementando el riesgo de degradación ambiental, aspectos que la reciente legislación minera actual en el Perú viene regulando y limitando.

7 La fijación o constitución de los precios de los metales se da en las bolsas de metales, siendo la de Londres y la de Nueva York las más representativas, podemos agregar a ellas los precios de principales productores, los que son tomados como referencia, para la formalización de los contratos de compra y venta.

8 La mayoría de las transacciones de producciones minerometalúrgicas toman como referencia los precios que se constituyen principalmente en la London Metal Exchange y el Comex. 


\section{Ysaac Ospino Edery}

Los mayores montos de inversión directa en minería provienen de capitales foráneos, siendo aquellos que provienen tanto de los EEUU como del Reino Unido los que lideran el sector, con alrededor de un $70 \%$ del total invertido, seguidos de los canadienses y chinos, que se presentan muy activos. Así mismo, también se aprecian montos de países que compiten con el nuestro en la actividad minera del cobre, como Chile, con la Cía. Minera Anaconda S.A y la Corporación Nacional del Cobre (Codelco).

Un aspecto a resaltar sobre el aumento del valor de la producción, tanto por el efecto de mayores precios como por incremento de la producción como resultado de mayores inversiones mineras, es que se ha constituido en la actividad que más ha incrementado su participación en la estructura tributaria en los últimos años. El aporte del sector representa cerca del $30 \%$ del impuesto a la renta de tercera categoría, se tiene así que entre los años 1995 y 2005 esa contribución pasó de alrededor de S/650 millones a S/3,200, situación que ha repercutido en un importante aumento del canon minero.

\section{La política minera, 1993-2014}

En la tercera elección democrática de un presidente posterior a los 12 años del gobierno militar, es electo el presidente Alberto Fujimori, quien recibe al país en una situación bastante crítica, tanto para la economía como para la sociedad en su conjunto, tan es así que la inflación acumulada en el periodo que duró el gobierno (previo) del presidente Alan García llegó a cerca de 2.2 millones por ciento, con el consecuente deterioro del nivel de vida y empobrecimiento de más de la mitad de la población, situación que a finales del 2013 no se había logrado mayormente su reversión, y con una actividad minerometalúrgica prácticamente estancada en lo que se refiere a la inversión foránea principalmente.

Entre las medidas que se implementan para promover y modernizar la actividad minera, se encuentran los D.L. 662, D.L. 708, D.L. 757 y D.L. 818 promulgados el año 1991, a los cuales también se les denominó "Decreto Legislativo de Promoción de Inversiones en el sector minero/ Ley Marco para el Crecimiento del Sector Privado", al amparo de los que se privatiza la comercialización interna y externa de minerales y metales, se da plena libertad al envío de utilidades, se otorgan exoneraciones deducciones y estabilidad tributaria a la inversión minera; así mismo se introdujeron 


\section{Pensamiento Crítico Vol. ᄅl, No 2}

normativas dirigidas a limitar y disminuir la contaminación ambiental (PAMA) y otros complementarios a fin de reforzar la promoción de la actividad minera, como la privatización de las concesiones, minas y refinerías de propiedad del Estado; todas dirigidas a desaparecer la actividad minerometalúrgica del Estado.

Bajo el auspicio de la nueva política sobre inversiones y el tratamiento al capital extranjero (exoneraciones tributarias, etc.), a lo que se sumó el mejoramiento del mercado mundial impulsado por las economías emergentes teniendo a la China e India como locomotoras, las inversiones en minería comenzaron a registrar un nivel de crecimiento significativo. Tan es así que, apreciando el cuadro 1 , tenemos que a principios de la década de los años 2000 está fue de alrededor de 1,500 millones, para luego reportar un acumulado cercano a los 30,000 millones entre el 2010 y 2013. Marco legal que ha continuado sin mayores modificaciones importantes en los gobiernos siguientes de Valentín Paniagua, Alejandro Toledo, Alan García y Ollanta Humala.

CUADRO 1

Inversión minera privada (Millones de US\$)

\begin{tabular}{|c|c|c|c|c|c|c|c|}
\hline & 1995 & 2000 & 2005 & 2010 & 2011 & 2012 & 2013 \\
\hline Total & 507 & 1500 & 1086 & 4025 & 7243 & 8568 & 9723 \\
\hline
\end{tabular}

Fuente: Boletín estadístico de minería MEM, 2013.

\section{Una perspectiva económica del mercado de metales (refinados y concentrados)}

\section{La oferta}

Se caracteriza por estar constituida por todas aquellas producciones de minerales, concentrados, fundidos y refinados que nuestro país no tiene la capacidad de poder absorber (consumo local/consumo interno), por lo que los saldos excedentes no consumidos internamente son (vendidos al exterior) exportados ${ }^{9}$.

9 Podemos inferir que la oferta mundial es una sumatoria/agregado de toda aquella producción que se ofrece externamente/ exporta y que no puede consumirse de manera interna. Se puede agregar a esta producción a aquella que proviene de la recuperación de la chatarra (secundaria). 


\section{Ysaac Ospino Edery}

Los ofertantes, tanto del estrato de la pequeña, mediana y gran minería, se comportan como tomadores de precios, (costas) que se constituyen en la bolsas de metales más representativas, como la "London Metal Exchange y el Comex", para la valorización de los contratos de compraventa, no obstante mantienen la racionalidad de a mayor precio, mayor producción ofertada.

Esta situación nos puede llevar a concluir que se da una forma de mercado de competencia perfecta para la materialización de las operaciones de compraventa, en línea con un comportamiento precio aceptante de los productores. "Un productor es precio- aceptante cuando sus acciones no pueden afectar el precio de la mercadería o servicio que vende". Como resultado, un productor precio aceptante considera el precio del mercado como dado, cuando existe suficiente competencia.

Dado que son las bolsas de metales las que generan los precios que van a servir de referencia para toda operación que se efectiviza fuera de ellas, podemos inferir que debe darse una correlación estrecha, entre el precio del mercado y el precio de exportación (venta). "En un mercado perfectamente competitivo, todos los participantes del mercado tanto productores como consumidores son precio aceptantes. Es decir, ni las decisiones de compra realizadas por los compradores individuales ni las decisiones de producción de los productores individuales afectan el precio del mercado del bien, no obstante cabe resaltar que el modelo de competencia perfecta no puede ser apropiado para todos los mercados" ${ }^{2}$.

La evidencia empírica se expresa en el cuadro 2, que estima corroborar lo anteriormente mencionado. Para el periodo comprendido entre los años 1990-2013 (23 años), por un lado consideramos el precio que adquirieron las exportaciones en valores FOB tanto para el cobre, el zinc y el plomo, mientras que por el otro las cotizaciones en términos CIF Settlement, generados en la Bolsa de Metales de Londres (LME) promedio anual.

Deduciendo la correlación entre los valores de venta por exportaciones obtenidas, así como por las cotizaciones referenciales, se tiene que tanto para el cobre, el zinc y el plomo, estas se ubican cerca de uno ( $\mathrm{r}$ próximo a 1) para el periodo analizado, lo que se interpreta como una alta correlación o relación que coadyuva a explicar el comportamiento precio aceptante de los ofertantes de producciones minerometalúrgicas.

10 Dada la múltiple y diversa calidad de la producción minerometalúrgica, se realizan ajustes en la valorización final. 


\section{Pensamiento Crítico Vol. ᄅl, № 2}

\section{La demanda}

La estructura de la demanda para el caso de nuestra producción minerometalúrgica o la foránea tiene un comportamiento complejo, a la cual podemos identificar, tanto por producto como por sujeto demandante. Tenemos así que en el primer caso, por producto, hay demandantes de concentrado, fundido y refinado; mientras que en el segundo, por sujeto, se ubican a las fundiciones, refinerías e industria para cada metal en particular, sea este cobre, zinc o plomo.

Los concentrados son parte de la cadena de valor agregado cuya característica es que su contenido fino (ley) por TM fluctúa entre $25 \%$ y $60 \%$, ya que todavía tienen que ser fundidos y refinados para ser consumidos por la industria. Este tipo de producto (concentrados varios) representa los mayores volúmenes de producción, así como de mayor demanda, tanto en el caso del $\mathrm{Cu}, \mathrm{Zn}$ y $\mathrm{Pb}$. Son las fundiciones y refinerías las demandantes de este tipo de producción, las que no son muy numerosas en el mercado. En nuestro país, a manera de ejemplo, solo tenemos 2 refinerías para $\mathrm{Cu}, 2$ para el $\mathrm{Zn}$ y una para $\mathrm{el}^{\mathrm{Pb}^{11}}$.

\section{CUADRO 2}

Evolución de los precios de exportación, cotizaciones CIF Settlement registradas en la bolsa de metales de Londres

\begin{tabular}{|c|c|c|c|c|c|c|}
\hline \multicolumn{2}{|c|}{ Precios de Exportacion FOB } & En US\$/Lb & \multicolumn{2}{c|}{ Cotización CIF Setlement } & \multicolumn{2}{c|}{ LME (Media) } \\
\hline AÑOS & Cobre & Zinc & Plomo (2) & Cobre & Zinc & Plomo \\
\hline 1990 & 111.1 & 36 & 53.4 & 120.72 & 68.55 & 36.72 \\
\hline 1991 & 102.2 & 31.9 & 40 & 105.91 & 50.66 & 25.27 \\
\hline 1992 & 98.2 & 33.1 & 40.9 & 103.45 & 56.24 & 24.55 \\
\hline 1993 & 82.5 & 22.6 & 29.8 & 86.77 & 43.63 & 18.44 \\
\hline 1994 & 96.5 & 25.5 & 49.2 & 104.7 & 45.29 & 24.86 \\
\hline 1995 & 130.2 & 29.1 & 59.5 & 133.18 & 46.78 & 28.62 \\
\hline 1996 & 100.4 & 30.3 & 61.7 & 104.14 & 46.52 & 35.12 \\
\hline 1997 & 99.2 & 37.5 & 51.6 & 103.28 & 59.75 & 28.32 \\
\hline 1998 & 72.6 & 30.7 & 44 & 75.02 & 46.42 & 23.98 \\
\hline 1999 & 67.6 & 31.3 & 36.2 & 71.32 & 48.82 & 22.8 \\
\hline 2000 & 79.9 & 28.4 & 35.8 & 82.34 & 51.16 & 20.59 \\
\hline
\end{tabular}

11 Para el cobre, la refinería de la Doe Run en La Oroya e Ilo; para el Zn, la refinería de Cajamarquilla y Doe Run; para el Pb, Doe Run. 


\section{Ysaac Ospino Edery}

\begin{tabular}{|c|c|c|c|c|c|c|}
\hline 2001 & 65.2 & 20.7 & 35.1 & 71.6 & 40.17 & 21.6 \\
\hline 2002 & 62.7 & 17.2 & 34.9 & 70.74 & 35.32 & 20.53 \\
\hline 2003 & 72.6 & 20.3 & 35.3 & 80.7 & 37.54 & 23.36 \\
\hline 2004 & 119.5 & 25.3 & 62.7 & 129.99 & 47.53 & 40.21 \\
\hline 2005 & 160 & 33.5 & 69 & 166.87 & 62.68 & 44.29 \\
\hline 2006 & 277.3 & 84.9 & 85.6 & 304.91 & 148.56 & 58.5 \\
\hline 2007 & 291.5 & 90.9 & 112.5 & 322.93 & 147.07 & 117.03 \\
\hline 2008 & 272 & 47 & 100 & 315.51 & 85.04 & 94.83 \\
\hline 2009 & 214 & 39 & 72 & 233.52 & 75.05 & 77.91 \\
\hline 2010 & 320.6 & 58.5 & 93 & 342.28 & 98.18 & 90.61 \\
\hline 2011 & 385.3 & 68.6 & 111.4 & 400.2 & 95.9 & 108.97 \\
\hline $2012(1)$ & 346.3 & 60.4 & 99.1 & 360.55 & 88.35 & 93.54 \\
\hline 2013$)(1)$ & 317.4 & 59.4 & 94.4 & 332.31 & 86.95 & 97.17 \\
\hline
\end{tabular}

Fuente: Memorias BCR (1990-2013), Elaboración propia, 1 preliminar, 2 Incluye contenido de Plata.

De lo anterior, podemos inferir que tanto las fundiciones y las refinerías tienen una mejor posición al ejercer su opción de compra en lo que respecta a los diferentes términos que se consideran en un trato comercial de compraventa, cuando se trata de concentrados.

En tanto, se da una posición de demanda más elástica cuando se trata de la comercialización de refinados, dado que los compradores/demandantes constituyen la industria en general de características varias, como de un mayor número, tamaño y actividad.

Podemos considerar la demanda de los no ferrosos como commodities que, al igual que la del resto de metales, se comporta como un componente del PBI y es, en definitiva, el crecimiento económico el que determina su mayor requerimiento.

\section{Factores que intervienen en la determinación de los precios de la produc- ción minerometalúrgica}

Frecuentemente vemos o escuchamos que los precios de los metales subieron o bajaron por diferentes factores, los cuales no dependen del comportamiento económico de nuestro país, sino que están sujetos a determinadas situaciones de carácter social, 


\section{Pensamiento Crítico Vol. ᄅl, № 2}

económico; vale decir, coyunturas externas que se dan en las más importantes plazas demandantes, por lo que se constituye en imprescindible e importante apreciar su evolución.

Dado que en las diferentes operaciones de compraventa interna y externa que realiza la pequeña, mediana y gran minería, ya sea de minerales, concentrados o refinados, se utilizan fórmulas para su valoración (ver entrecomillado siguiente), las que tienen como referencia los precios que se determinan en las bolsas de metales más representativas $\mathrm{u}$ otras organizaciones que cumplen una función similar.

"Los concentrados se valorizan a los precios de los metales menos descuentos/ deducciones por costos de tratamiento, pérdidas y otros factores".

Los precios de los minerales, concentrados y refinados más representativos para nuestra economía (cobre, plomo, plata, zinc, oro, llámense metales no ferrosos) son comúnmente el reflejo de las condiciones que imperan en cada momento en el mercado mundial. En el cual participan compradores y vendedores de toda magnitud, influenciando de manera decisiva en las fluctuaciones y la estabilidad de los precios.

Es así como los grandes compradores/corporaciones de los países industrializados (Estados Unidos, Japón, Alemania, Francia, Italia, España y otros de la Comunidad Económica Europea, y los llamados emergentes como China, India, Brasil, etc.) juegan un papel decisivo en el funcionamiento del mercado mundial, donde los efectos de las situaciones políticas, económicas, financieras que atraviesan estos países repercuten en los precios de los metales y en las expectativas futuras en cuanto a las cotizaciones de los mismos.

Es notorio que los factores que afectan la fijación de los precios de los metales puedan darse por un exceso de producción del metal, el cual se hace sentir rápidamente en el mercado, igualmente un aumento violento en la demanda influye de inmediato en los precios que se registran, de comportamiento elástico. A los factores mencionados, se suman otros que en gran parte influencian directamente en la generación de los precios al contado y a futuro, como por ejemplo: la existencia de metales en stock en poder de los productores, comerciantes, consumidores y las bolsas de metales, así como aquellas provenientes de recuperación de la chatarra. 


\section{Ysaac Ospino Edery}

De manera adicional, la calidad del comprador o vendedor concediendo descuentos, premios de diversa índole, facilidades de pago, etc.

\section{Evolución del mercado mundial de metales ( $\mathrm{Cu}, \mathrm{Zn}$ y Pb), 1995-2014}

Para el caso del mercado mundial de metales, se hará referencia particular al comportamiento de los principales y más representativos actores que constituyen la oferta y la demanda, y de manera específica a la evolución que sigue el $\mathrm{Cu}$, por ser el más representativo de los metales no ferrosos primarios $(\mathrm{Zn}$ y $\mathrm{Pb})$ que el Perú produce y exporta.

Como se mencionó en el párrafo anterior, la oferta está constituida básicamente por aquellos volúmenes que se producen, no se consumen internamente y que son exportados, sea en su forma de mineral de alta ley, concentrados, fundidos (blíster para el caso del cobre) y refinados, y la demanda/consumo conformada por las fundiciones, las refinerías y la industria en general (de difícil identificación por la cuantía y diversificación de sus participantes).

\section{CUADRO 3}

Producción de Cu mina, miles de TMF

\begin{tabular}{|l|c|c|c|c|c|}
\hline País/Año & 1996 & 2000 & 2005 & 2010 & 2013 \\
\hline Chile & 3115.8 & 4602.0 & 5320.5 & 5418.9 & 5776.0 \\
\hline Estados Unidos & 1918.4 & 1444.1 & 1140.0 & 1110.0 & 1240.1 \\
\hline Perú & 484.2 & 553.9 & 1009.9 & 1247.2 & 1375.6 \\
\hline China & 439.1 & 592.6 & 761.6 & 1179.8 & 1707.7 \\
\hline Australia & 548.0 & 832.0 & 930.0 & 870.0 & 996.0 \\
\hline Rusia & 520.0 & 580.0 & 804.7 & 703.3 & 720.0 \\
\hline Indonesia & 525.9 & 1005.5 & 1064.2 & 871.2 & 494.0 \\
\hline Canadá & 688.4 & 639.9 & 594.5 & 522.2 & 631.9 \\
\hline Zambia & 339.7 & 249.3 & 441.4 & 731.7 & 839.3 \\
\hline Polonia & 472.6 & 454.1 & 511.5 & 425.4 & 429.4 \\
\hline Kazajistan & 237.5 & 430.2 & 435.6 & 403.7 & 538.0 \\
\hline Principales países & 9289.6 & 11383.6 & 13013.9 & 13483.3 & 14748.0 \\
\hline Resto del Mundo & 1821.1 & 1862.9 & 2112.6 & 2631.0 & 3539.7 \\
\hline Total Mundial & 11110.7 & 13246.5 & 15126.5 & 16114.3 & 18287.7 \\
\hline
\end{tabular}

Fuente: Anuario 2014 COCHILCO. 
Del cuadro 3, se tiene que Chile mantiene su liderazgo como productor de cobre, con alrededor de $30 \%$ del total mundial, acumulado que se ha incrementado en cerca de 65\% entre 1996 y 2013. Cabe resaltar el caso de la producción del Perú, que aumenta su obtención en cerca de $300 \%$, aspecto que se atribuye a la ley de promoción minera ya mencionada anteriormente, así como a la evolución positiva del mercado reflejado en mayores precios, que permite el ingreso de nuevos proyectos y producciones con leyes marginales.

En lo que respecta a los refinados, ver cuadro 4, que es requerido por una amplia variedad de industrias que lo demandan, es notable el incremento de la producción china para abastecer su mercado interno, caso similar al de otros países industrializados del mercado libre europeo y economías como la de los BRICS.

CUADRO 4

Producción de Cu refinado, en miles de TMF

\begin{tabular}{|l|c|c|c|c|c|}
\hline País/Año & 1996 & 2000 & 2005 & 2010 & 2013 \\
\hline China & 1119.1 & 1371.1 & 2600.4 & 4540.3 & 6838.8 \\
\hline Chile & 1748.2 & 2668.3 & 2824.0 & 3423.9 & 2754.9 \\
\hline Japón & 1251.4 & 1437.4 & 1395.3 & 1548.1 & 1468.1 \\
\hline Estados Unidos & 2352.4 & 1790.0 & 1260.0 & 1097.7 & 1040.0 \\
\hline Rusia & 599.2 & 824.0 & 967.5 & 900.0 & 873.6 \\
\hline India & 39.3 & 259.1 & 517.6 & 647.5 & 619.4 \\
\hline Rep. del Congo & 42.2 & 29.0 & 2.5 & 254.0 & 642.6 \\
\hline Zambia & 317.1 & 226.2 & 465.0 & 767.0 & 629.2 \\
\hline Alemania & 670.8 & 709.5 & 638.3 & 704.2 & 679.7 \\
\hline Corea del Sur & 246.2 & 470.5 & 526.6 & 556.0 & 604.0 \\
\hline Polonia & 424.7 & 486.0 & 560.3 & 547.1 & 565.1 \\
\hline Australia & 311.4 & 484.0 & 471.0 & 424.0 & 480.0 \\
\hline España & 264.0 & 315.8 & 308.0 & 347.4 & 351.0 \\
\hline Bélgica & 386.0 & 423.0 & 382.9 & 389.0 & 389.4 \\
\hline
\end{tabular}




\section{Ysaac Ospino Edery}

\begin{tabular}{|l|c|c|c|c|c|}
\hline México & 242.0 & 399.1 & 386.8 & 247.0 & 350.1 \\
\hline Perú & 342.0 & 324.4 & 344.8 & 240.6 & 271.8 \\
\hline Canadá & 559.2 & 551.4 & 515.2 & 319.6 & 321.5 \\
\hline Kazajistan & 267.1 & 394.7 & 418.4 & 323.4 & 353.5 \\
\hline Indonesia & 00 & 158.4 & 262.9 & 277.5 & 214.3 \\
\hline Brasil & 172.1 & 185.3 & 199.0 & 222.3 & 271.8 \\
\hline Bulgaria & 22.3 & 32.5 & 60.5 & 216.0 & 230.0 \\
\hline Principales países & 11376.7 & 13539.7 & 15107 & 17992.6 & 19948.8 \\
\hline Resto del mundo & 1379.7 & 1264.8 & 1563.0 & 1222.5 & 1374.5 \\
\hline Total mundial & 12756.4 & 14804.5 & 16670.0 & 19215.1 & 21323.3 \\
\hline
\end{tabular}

Fuente: Anuario 2014 COCHILCO

El caso de la producción peruana de refinados la podemos considerar crítica, dado que luego de haber alcanzado una cantidad superior a las 340,000 TMF para mediados de la década de los años 2000, se reduce a niveles menores de las 300,000 TMF, contexto atribuible a la menor operación de la refinería de La Oroya gestionada por Doe Run (paralización), escenario negativo si consideramos que uno de los objetivos de la actividad metalúrgica es dar cada vez más valor agregado a la producción minera. Este aspecto no se puede atribuir a la coyuntura económica externa, sino al descuido y desconocimiento de los gobiernos de turno con respecto al desarrollo sostenido de este sector, pues ha dejado en manos privadas su desenvolvimiento ${ }^{12}$.

En el cuadro 5 siguiente, se aprecia la evolución mundial de las importaciones y el consumo de Cu refinado entre los periodos 1996/2013, donde resalta el peso de China, con una participación cercana al $40 \%$ del total mundial de las importaciones y $47 \%$ en el consumo.

12 En el Perú en los últimos 40 años no se han construido/ implementado, refinerías de $\mathrm{Cu}, \mathrm{Zn}$ y $\mathrm{Pb}$, aspecto que nos indica la poca importancia que se ha tenido para los gobiernos de turno esta estratégica actividad para el desarrollo económico. 
CUADRO 5

Importación - Consumo de Cu Refinado en Miles de TMF

\begin{tabular}{|c|c|c|c|c|c|c|}
\hline \multirow[t]{2}{*}{ País/Año } & \multicolumn{2}{|c|}{1996} & \multicolumn{2}{|c|}{2005} & \multicolumn{2}{|c|}{2013} \\
\hline & Importa & Consumo & Importa & Consumo & Importa & Consumo \\
\hline China & 149.7 & 1192.7 & 1222 & 3639.1 & 3205.8 & 9830.1 \\
\hline Hong Kong & 89 & 4.8 & 47.1 & 4.8 & 4.6 & 4.8 \\
\hline Japón & 460.4 & 1479.6 & 73.9 & 1226.7 & 41.3 & 996.4 \\
\hline Estados Unidos & 620.2 & 2621.4 & 977.1 & 2270 & 729.7 & 1826.3 \\
\hline Singapur & 190.8 & 13.7 & 40.6 & 10 & 1.1 & 9.7 \\
\hline India & 131.4 & 140 & 21.8 & 398 & 9.7 & 423.3 \\
\hline Italia & 437.6 & 503.8 & 652.1 & 676.1 & 558.8 & 551.6 \\
\hline Malasia & 143.9 & 143.9 & 281.1 & 224.4 & 517.8 & 182.9 \\
\hline Alemania & 450.4 & 960 & 624.7 & 1176.6 & 679.7 & 1135.6 \\
\hline Corea del Sur & 351 & 598.4 & 428 & 852.6 & 298.1 & 722.3 \\
\hline Tailandia & 154.80 & 154.6 & 234.5 & 240.8 & 247.9 & 247.7 \\
\hline Reino Unido & 327.8 & 396 & 181.9 & 165.4 & 34.7 & 22.8 \\
\hline España & 21.2 & 191 & 69 & 292 & 60.9 & 298.3 \\
\hline Bélgica & 75.5 & 332.2 & 9.5 & 320.4 & 59.2 & 218 \\
\hline México & 18.6 & 192 & 52.3 & 471.2 & 63.6 & 333.9 \\
\hline Taiwán & 545.6 & 543.7 & 640.3 & 638.4 & 438.1 & 437.5 \\
\hline Canadá & 28.7 & 218.3 & 64.5 & 289.5 & 2.7 & 157.4 \\
\hline Francia & 456 & 518.2 & 516.9 & 472.2 & 230.4 & 200.6 \\
\hline Indonesia & 105.4 & 104.9 & 21.1 & 246.9 & 100.5 & 243.9 \\
\hline Brasil & 102.9 & 233.1 & 167.7 & 333.9 & 245.8 & 423.3 \\
\hline Turquia & 48.6 & 160 & 224 & 316.8 & 362.9 & 453.1 \\
\hline Principales países & 4909.5 & 10702.3 & 6550.1 & 14265.8 & 7893.3 & 18719.5 \\
\hline Resto del mundo & 438.9 & 1712.1 & 337.2 & 2550.9 & 494.3 & 2320.5 \\
\hline Total Mundial & 5348.4 & 12414.4 & 6887.3 & 16816.7 & 8387.6 & 21040 \\
\hline
\end{tabular}

Fuente: Anuario Cochilco 2014 
El cuadro anterior nos presenta la evidencia empírica del consumo de la China, EE.UU., Alemania y Corea, así como su situación deficitaria de abastecimiento interno, razón por la cual direccionan sus requerimientos a producciones exportables de países como el Perú. El cuadro 6 nos muestra la participación de los países antes mencionados como los más importantes destinatarios de nuestra producción, lo cual también nos indica cuán dependientes nos constituimos de la evolución económica de la China y Corea del Sur para las exportaciones de $\mathrm{Cu}, \mathrm{Zn}$ y $\mathrm{Pb}$.

CUADRO 6

Destinos de las exportaciones nacionales (2014)

\begin{tabular}{|l|c|c|c|c|c|c|}
\hline \multicolumn{1}{|c|}{ País } & Cobre & & Plomo & & Zinc & \\
\hline China & $\begin{array}{c}\text { US \$llones } \\
\text { Japón }\end{array}$ & $\%$ & $\begin{array}{c}\text { US\$ } \\
\text { Millón }\end{array}$ & $\%$ & $\begin{array}{c}\text { US\$ } \\
\text { Millón }\end{array}$ & $\%$ \\
\hline Alemania & 4336 & 49.23 & 407 & 26.83 & 396 & 26.31 \\
\hline Brasil & 753 & 8.55 & 45.2 & & 137.1 & 9.11 \\
\hline Italia & 521 & 5.92 & & & 130.4 & 8.67 \\
\hline Corea del Sur & 392 & 4.45 & & & & \\
\hline Estados Unidos & & 4.20 & 354.9 & 23.43 & 242.4 & 16.11 \\
\hline Canadá & & & 95.5 & 6.30 & 54.6 & 3.63 \\
\hline Federación Rusa & & & 601.3 & 19.89 & 48.9 & 3.25 \\
\hline India & & & 30.2 & 2.00 & & \\
\hline España & & & & & 225.9 & 15.02 \\
\hline Taiwán & & & & & 67.6 & 4.49 \\
\hline Bélgica & & & & & 40.5 & 2.69 \\
\hline Otros & 1902 & 21.60 & 43.1 & 3.00 & 161.2 & 11 \\
\hline Total & 8807 & 100 & 1515 & 100 & 1504 & 100 \\
\hline
\end{tabular}

Fuente: Anuarios Ministerio de Energía y Minas 2010/2014. Perú 


\section{Pensamiento Crítico Vol. ᄅl, № 2}

Tomando de manera conjunta el consumo y las importaciones de China, Estados Unidos, Alemania, Japón y Corea del Sur, estos representan una cifra cercana al $70 \%$ del total mundial, volumen que nos indica la concentración y la dependencia que se adquiere de la evolución de las economías de estos países. Así, apreciando de manera particular los cambios y las oscilaciones que se registran en su PBI (cuadro 7), nos resulta un buen indicador de las tendencias que adquirió este metal en el mercado.

Denominamos evolución del mercado mundial a las fluctuaciones del PBI como principal indicador de la economía de los más representativos demandantes (consumidores) de los no ferrosos ${ }^{13}(\mathrm{Cu}, \mathrm{Pb}$ y $\mathrm{Zn})$, en sus formas de concentrados por las fundiciones/refinerías y refinados para ser utilizados por sus industrias, y la oferta a aquella producción, sea de concentrados, fundidos, refinados no consumidos internamente y que luego son exportados.

El cuadro 7 hace referencia de manera particular al Cu por ser el más representativo en el aporte a nuestra economía de los no ferrosos que producimos y exportamos. Así también, se aprecia en este cuadro a China, que en el periodo de análisis (1995-2013) ha evidenciado un crecimiento permanente de su PBI, que llegó a mediados de la década de los 2000 a superar el 14\%, cifra que la convierte, conjuntamente con la India, como las de mayor expansión de este indicador a nivel mundial. A ellas se agrega Corea del Sur, peso económico por el cual también se les ha denominado como las locomotoras de la economía mundial del siglo XXI. Del análisis de la evidencia empírica de los cuadros mencionados ${ }^{14}$, resulta que los hechos registrados nos indican que la producción y la exportación minerometalúrgica del $\mathrm{Cu}, \mathrm{Pb}$ y $\mathrm{Zn}$ ha sido influenciada positivamente por la evolución del mercado mundial consumidor, expresado por mayores montos de inversión, volúmenes de producción, exportación, precios de exportación, mayor recaudación por impuestos que contribuyen a financiar un mayor canon minero.

13 Como se hizo mención en el párrafo anterior, se hará el análisis a base de la producción de cobre, por ser el más representativo entre los no ferrosos que produce el Perú.

14 Cuadros del 1 al 9. 


\section{Ysaac Ospino Edery}

\section{CUADRO 7}

\begin{tabular}{|l|c|c|c|c|c|c|c|c|c|c|c|c|}
\hline & 1995 & 2000 & 2005 & 2006 & 2007 & 2008 & 2009 & 2010 & 2011 & 2012 & 2013 & 2014 \\
\hline Pais/Año/PBI & & & & & & & & & & & & \\
\hline China & 11 & 11.4 & 11.4 & 12.7 & 14.2 & 9.6 & 9.2 & 10.6 & 9.5 & 7.8 & 7.7 & 7.3 \\
\hline Estados Unidos & 2.7 & 4.1 & 3.3 & 2.7 & 1.8 & -0.3 & -2.8 & 2.5 & 1.6 & 2.3 & 2.2 & 2.4 \\
\hline Alemania & 1.7 & 3 & 0.7 & 3.7 & 3.3 & 1.1 & -5.6 & 4.1 & 3.7 & 0.4 & 0.3 & 1.6 \\
\hline Corea del Sur & 8.9 & 8.8 & 3.9 & 5.2 & 5.5 & 2.8 & 0.7 & 6.5 & 3.7 & 2.3 & 2.9 & 3.3 \\
\hline Japon & 1.9 & 2.3 & 1.3 & 1.7 & 2.2 & -1 & -5.5 & -4.7 & -0.5 & 1.8 & 1.6 & -0.1 \\
\hline Brasil & 4.4 & 4.4 & 3.1 & 4 & 6 & 5 & 0.2 & 7.6 & 3.9 & 1.8 & 2.7 & 0.1 \\
\hline India & 7.6 & 3.8 & 9.3 & 9.3 & 9.8 & 3.9 & 8.5 & 10.3 & 6.6 & 5.1 & 6.9 & 7.3 \\
\hline & & & & & & & & & & & & \\
\hline Prod. CU. MILES TMF & 410 & 553.9 & 1010 & 1048 & 1190 & 1268 & 1276 & 1247 & 1235 & 1299 & 1376 & 1380 \\
\hline Prod Perú. Ref Mils TMF & 261.8 & 324.4 & 344.8 & 333.8 & 237.7 & 303.8 & 263.6 & 240.6 & 227.3 & 210.1 & 271.8 & 263.6 \\
\hline Export-Cu-Miles TMF & 387 & 529 & 984.2 & 980.6 & 1121.9 & 1243.1 & 1246.2 & 1256.1 & 1262.2 & 1405.6 & 1404 & 1402 \\
\hline
\end{tabular}

Fuente: Banco Mundial. Anuarios Mineros de energía y minas perú 2015

\section{Conclusiones}

1. El actual marco normativo de la actividad minerometalúrgica ha excluido al Estado de una mayor fiscalización de la producción y comercio exterior de las producciones resultantes, al constituirse en un limitado observador.

2. Bajo el auspicio de la actual política sobre inversiones y el tratamiento al capital extranjero (exoneraciones tributarias, etc.), a lo que se sumó el mejoramiento del mercado mundial impulsado por las economías emergentes teniendo a la China $e$ India como locomotoras, las inversiones, la producción y las exportaciones minerometalúrgicas de cobre, zinc y plomo comenzaron a presentar un nivel de crecimiento significativo.

3. La evolución del mercado mundial ha influenciado de manera positiva en la producción y exportación minerometalúrgica de los metales no ferrosos primarios en el Perú, periodo 1995-2013.

4. Se da una dependencia no estratégica de las exportaciones minerometalúrgicas, respecto a la evolución del mercado chino y Corea del Sur, principalmente. 


\section{Pensamiento Crítico Vol. ᄅl, № 2}

\section{Referencias bibliográficas}

Banco Central de Reserva del Perú. Memorias Anuales (1990-2013). Lima.

Bologna, C.(1999). Lecciones de economía. Lima: Universidad San Ignacio de Loyola.

Cepal (2006). La importancia de la actividad minera en la economía y sociedad peruana. Santiago de Chile: Santillana Santos Miguel.

Cepal-Cochilco (2005). Determinación del precio spot del cobre en las bolsas de metales. Santiago de Chile.

Hernández, R., Fernández, C. y Bautista, P. (2007). Fundamentos metodológicos de metodología de la investigación. México: Mc Hill.

INEI (2013). Perú Compendio Estadístico 2013. Lima.

Instituto de Ingenieros de Minas del Perú (2010). Minería peruana contribución al desarrollo económico y social. Lima.

La Tiza. Asociación Latinoamericana de Zinc (2010). Guía para la comercialización de minerales y metales. Lima.

Ministerio de Energía y Minas del Perú. Anuarios mineros, 2000-2013. Lima.

Osinergmin- Dammert Lira, A., Molinelli Aristondo, F. (2007). Panorama de la minería en el Perú. Lima.

Ospino, Y. (2012). Una apreciación a la comercialización de la producción minero metalúrgica en el Perú, periodo 1970-2010. Pensamiento Crítico $N^{\circ} 17$. Revista de del Instituto de Investigaciones Económicas de la Facultad de Ciencias Económicas de la UNMSM. Lima. 